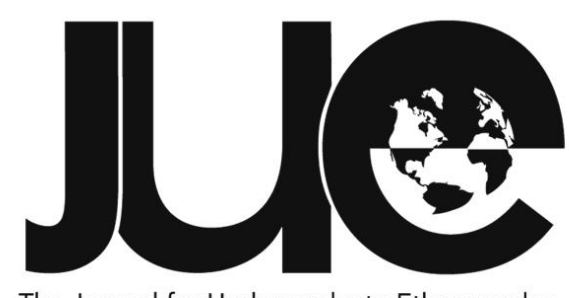

The Journal for Undergraduate Ethnography

\title{
Cycling in(to) Society: Integration and Social Mobility in Copenhagen
} Tanja Karen Jensen

\author{
University of Aberdeen-tanjen96@gmail.com
}

\section{ABSTRACT}

Integration and the processes involved are increasingly becoming more important in anthropological studies as the world is globalising. However, individual experiences of migrants, especially those of women, are often not considered in academic research. Therefore, I aim to include personal experiences of migrant women by studying those in the context of integration in Copenhagen. I conducted fieldwork over two months in the city of Copenhagen through participant observation in a cycling course created by the Red Cross, along with several informal interviews and five in-depth interviews with key informants. This article examines how integration is perceived, whether intersecting physical and social mobility can aid integration, and what impact gender has on these processes. Integration in this context is argued to be a form of social mobility, one that describes a forward movement into society. The process of integration for the women considered in this research is aided by cycling, as moving through the city physically promotes social mobility. Cyclists learn to navigate both the social and physical environment around them, and they gain access to services as well as opportunities in the labour market.

Keywords: social mobility; integration; gender; migrant women; cycling 


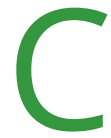
ycling is an essential part of everyday life in Copenhagen, but for newcomers in the city, adapting to this mode of transport is a difficult adjustment. The local Red Cross therefore organises cycling lessons for migrants, teaching them how to cycle and navigate the busy bike traffic in the city. The course is held at a small playground behind a primary school that has painted asphalt mimicking real roads. The playground is hidden behind the school but is connected to the rest of Copenhagen by a cycle highway, which is also the route I took to get there. I park my bike up against a shed and head toward the wooden picnic table where people are sitting (figure 1). Sandra, the team leader, springs up with a beaming smile on her face, and she welcomes me with a big hug. Meanwhile, a few people are very slowly cycling around in small circles on the asphalt. Those who cannot quite cycle yet seem to be pushing themselves forward with their feet. I notice everyone on a bicycle is a woman; the only males present are two of my fellow volunteers. Although there are clear differences in age and country of origin, all attendees wear the same yellow vests and bicycle helmets. Up until my first day as a cycling instructor, I thought of biking as a trivial part of everyday life that, to me, was just a way of getting from one place to the next. I did not give much thought to the fact that cycling was necessary for freedom and accessibility. I soon came to realise through teaching women from countries much different than my own that cycling could mean more than just physical mobility; indeed, cycling has a significant impact on social mobility as well.

By observing and speaking to women learning how to cycle through sessions organised by the Danish Red Cross, this research looks at the experiences of migrants,

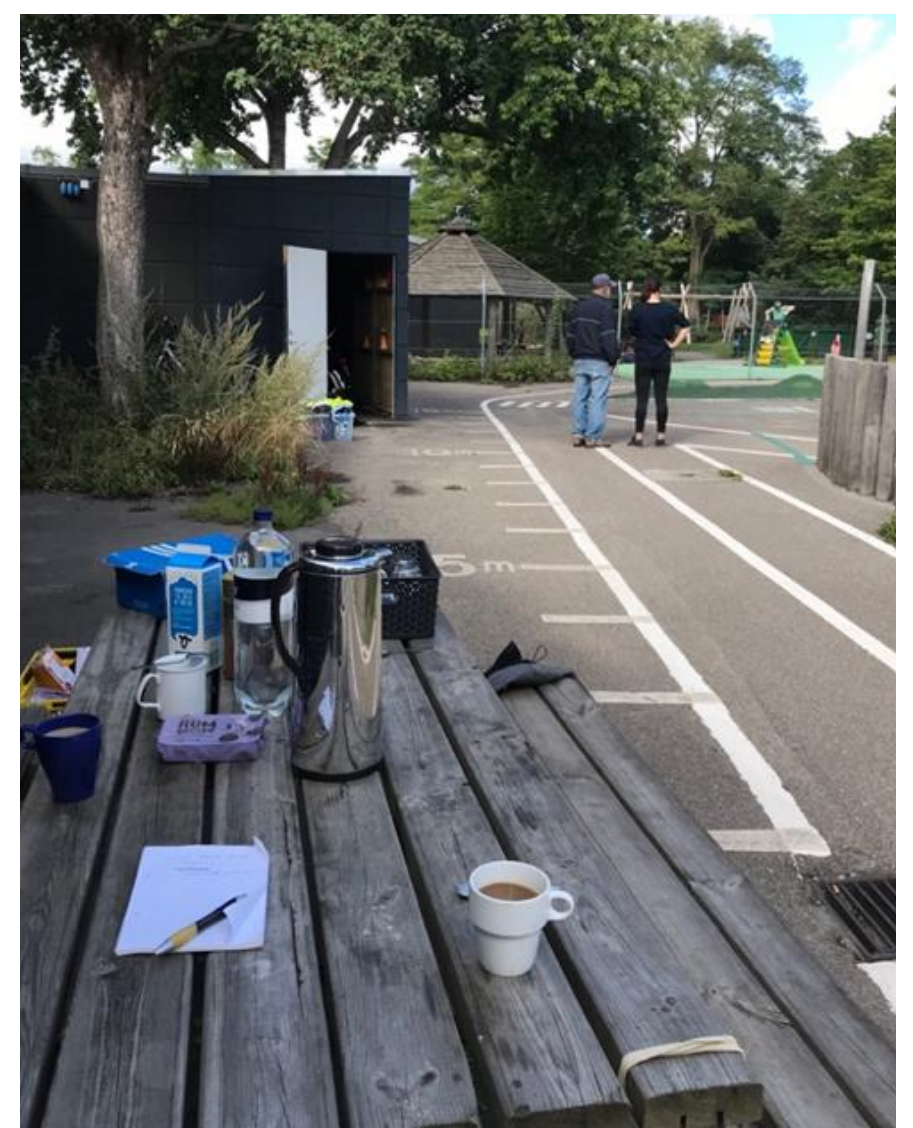

Figure 1: The cycling playground. As usual, there is coffee and cake for participants.

specifically women, as they integrate into Danish society. It seeks to understand how cycling and the process of learning this skill can contribute to individual migrants' integration in Copenhagen. Investigating the experiences of migrants is especially important in a relatively homogenous society such as Denmark since the strong sense of a shared national identity is often seen to be challenged by the influx of immigrants. Migration and integration are not only widely discussed in politics and media but also are prominent in everyday conversation. Since policies involving the process of integration often generalise immigrants and ignore individual experiences, I am interested in how individual migrants experience integration and how cycling may affect this experience. I argue that we must look beyond conventional definitions of social mobility and integration to include individual experiences and understand the impacts of these processes on migrant women specifically. I explored the experiences of migrant women in their process of integrating into Danish society through the concepts of social mobility and gender. These concepts have informed the research questions 
below, which then guided my fieldwork and analysis of integration through cycling.

1. What does the notion of integration entail for individual migrant women in Copenhagen? How do they perceive this process?

2. Can physical mobility lead to a better sense of social mobility and integration?

3. Does gender have an impact on the experiences of the process of social mobility and integration?

The research data is derived from official government publications, fieldnotes taken during participant observation at the cycling course, and informal interviews with its participants. My fieldwork and interviews were conducted while I was volunteering with the Red Cross in Copenhagen during August and September of 2019. The project formed around what I was able to do as a volunteer, since I was working with a large international charity and had to respect their policies. Fortunately, I was allowed to participate in the cycle training course that was one of their many projects aimed at migrants and social inclusion. My role as a volunteer was to train participants through simple steps to gain balance, provide enthusiastic encouragement, and instruct them in navigating traffic. During breaks, I was able to speak to some of the trainees and have short informal conversations with them about their experiences. I also contacted two informants outside of sessions so that I could conduct longer and more in-depth interviews. By participating in their training, I was able to observe informants interacting with each other and with the volunteers. The dissertation research proposal went through ethical clearing at the University of Aberdeen. Considering the ethics of the project, I made sure to inform the team leader, the volunteers, and the pupils that I would be doing research for my undergraduate dissertation while I volunteered. It was especially important to be transparent as a researcher because vulnerable people were involved in the process. Each informant was told participation was voluntary, anonymous, and that personal information such as names and email addresses were safely stored.
Approaching the integration of migrants through a gendered perspective became necessary after I had completed my fieldwork since I had only spoken to women. I found that being a woman myself gave me certain advantages when conducting fieldwork for this dissertation. The women I spoke with regularly confided in me and opened up to me easily about their experiences. I also noted that despite being a new volunteer, I was trusted by the trainees to instruct them and was even asked to give some one-on-one sessions during weekends. I had the advantage of conducting anthropological research at home, as being Danish myself meant that I could give insights about life in Denmark to the participants and help them practice the Danish language. This strengthened the relationships I had with informants. However, I was limited by the time constraints and irregularity of those who showed up to the cycling sessions. This meant that I was constantly forming new relationships and continuously had to work on gaining the trust of newcomers, which made getting into the details of their experiences and learning more thoroughly about each person very difficult.

To make sense of the ethnographic descriptions below, I will briefly introduce the team leader and my main informants from the cycling course (see table 1). Each of these women has been given a pseudonym to protect their confidentiality. Sandra is the team leader of this cycling group, and she has contact with the Red Cross and organises the cycling lessons. With help from volunteers, she keeps track of who is participating and their skill level. She has been involved in the lessons since they started five years ago, organised by the local library and community centre, before the Red Cross began funding the project. Brianna is the first cycle trainee I met and attended every single session I was at. She often brought her young daughter who wanted to learn how to cycle as well. Brianna is originally from Pakistan and moved to Copenhagen to be with her husband and reunite the family. Siri joined the cycling lessons for a few sessions since she had previous experience but needed proof of her ability to cycle in order to become a social care assistant. She had lived in Copenhagen since 2010 and moved here to be with her husband. 
Table 1: General information about the main participants in the study.

\begin{tabular}{|l|l|l|l|}
\hline Name & Country of Origin & Time lived in Denmark & Reason to participate \\
\hline Brianna & Pakistan & 7 months & $\begin{array}{l}\text { Had dreamed of learning how to cycle but was } \\
\text { never allowed to in her home country. }\end{array}$ \\
\hline Siri & Nepal & 9 years & $\begin{array}{l}\text { Needed proof of her ability to cycle to work as } \\
\text { a social care assistant. }\end{array}$ \\
\hline Kyra & India & 1 year & $\begin{array}{l}\text { Saw biking as an important part of living in Co- } \\
\text { penhagen and felt left out for her inability to } \\
\text { cycle. }\end{array}$ \\
\hline Lola & Armenia & 26 years & $\begin{array}{l}\text { Wanted to keep fit and keep her daughter } \\
\text { company as she learned. }\end{array}$ \\
\hline
\end{tabular}

Kyra, originally from India, moved to Copenhagen with her Belgian husband. She learned very quickly and found cycling exhilarating. Lola was inspired by her daughter to learn how to cycle, so they joined the lessons together. She had been in Copenhagen the longest, coming from Armenia in the 1990s. She started cycling both for convenience and to keep fit.

\section{Immigration Policies in Denmark: Past and Present}

Looking at the history of immigration in Denmark is necessary to provide context and a wider understanding of the integration process in the country's capital. Immigration to Denmark expanded during the economic boom of the 1960s as a shortage of labour attracted migrant workers to the country. At this time, the country lacked policies to support integration in terms of language, schooling, and welfare (Tesfaye 2017). The economic bust in the 1970s meant employment levels went down while immigration continued to increase (Olwig and Pærregaard 2011, 3). High levels of unemployment meant tensions between migrants and locals rose, and municipalities were overwhelmed with the uncontrollable influx of people. As a result, the attitude towards immigration changed and borders were closed again. The migrant population did not disappear, however, since most of the immigrants already living in Denmark remained (Tesfaye 2017).
In 1983, years after the initial wave of migrant workers, the first immigration law was put into place (Olwig and Pærregaard 2011). The law involved opportunities for asylum and new requirements for authorisation to bring family members into the country. Family reunification was granted automatically, meaning spouses of immigrants automatically gained citizenship (Folketinget 1983). This immigration law was, at the time, considered one of the most liberal in Europe (Olsen et al. 2017). Almost ten years after, in 1998, the first law specifically targeting issues of integration was drafted. It aimed to ensure equal opportunities for foreign newcomers in all aspects of life in Danish society, including work, politics, economics, religion, and culture. It intended to ensure that immigrants would quickly become self-sufficient and be given an understanding of the basic values and norms of Danish society (Hansen 2016).

Despite liberal laws and a progressive political climate, many Danish citizens and politicians perceived the influx of migrants as a threat to Danish national identity. This created a dramatic shift from one of the most liberal immigration policies in Europe to one of the most restrictive. Immigration has since been a major source of debate in Danish politics, especially during elections. In 2001, for example, the election of a conservative government led to more restrictive policies concerning foreign migrants. The updated "foreigner policy" (udlændingelov) created harsher regulations for immigrants and made 
residence permits much harder to attain (Hansen 2016). Similarly, the migrant crisis of 2015, referring to the thousands of migrants fleeing conflict in the Middle East and Africa and entering Europe, sparked new nation-wide discussion in Denmark on what to do about immigrants, immigration, and integration. Much like in 2001, the election following the crisis resulted in right-wing parties gaining more power compared to previous years. These parties passed new policies detrimental to the immigrant population. One, which came into effect in 2018, was the "masking ban" that prohibited face-covering in public, widely believed to be targeted at Muslim women. Another policy made it more difficult to acquire residence permits: refugees and families of immigrants entering the country could no longer qualify for permanent residency. Funding for integration efforts was cut, which meant the focus shifted from integrating incoming refugees to sending them home when possible (Ingvorsen 2019).

The most recent election in the summer of 2019 voted in a new prime minister from the left-wing Social Democrats, Mette Frederiksen. The election occurred during my fieldwork and was seen as a positive move toward more liberal immigration policies, since the antiimmigration Danish People's Party lost support after being the second biggest party for years. In reality, the Social Democrats are continuing the restrictive immigration policies created by the previous ruling power "Venstre" and the Danish People's Party. Despite enforcing policies created by right-wing parties, the Social Democrats are backed by a wide majority of the population favouring their known liberal views. As a result, the division between left- and rightwing immigration ideology is diminishing. In Denmark, non-western immigrants are seen as a threat to liberal politics and core values, as well as the perceived homogenous population in terms of ethnicity and religion. Denmark typically shares a strong sense of national identity that is grounded in ideals of Lutheranism, social democracy, and emphasis on the welfare state. As a consequence, migrants entering Denmark have a strong barrier to break through in order to become part of the Danish nation-state.
Currently, immigrants make up around 10\% of Denmark's population, with the largest number living in Greater Copenhagen (Danmarks Statestik 2018, 11). Since the late 1980s, immigration levels have remained higher than those of emigration, and the non-western immigrant population has increased significantly, now making up the majority of the migrant population (Tesfaye 2017; Danmarks Statestik 2018, 11-14). Although the population of immigrants in Denmark seems relatively small in comparison to other European countries, the aforementioned policies and political debates show the extensive impact migration has had on the country. Not only do they affect the lives of foreign migrants in Denmark, but also how these foreigners are perceived in local and public discourse.

\section{Cycling Culture in Copenhagen}

Copenhagen prides itself in being the "world's best cycling city," and its cycling culture is very important to those who live there. It has become more than just a form of transportation; it is a cultural symbol. Cycling is a symbol of equality since it is the best way to navigate through the city and most people living in Copenhagen use bicycles no matter their background or status. Getting around with a car or public transport is simply impractical in comparison. The fact that cycling is essential for life in Copenhagen is immediately noticeable when walking around anywhere in the city; you are always surrounded by bicycles. This often intimidates those who set foot in Copenhagen for the first time and are not used to seeing hundreds of cyclists dominate the traffic. Though it may be daunting to join the locals in cycling, it is inevitably the best way to get around. By cycling in Copenhagen, you become a part of the cityscape. Therefore, considering Copenhagen's cycling culture is noteworthy when exploring the experiences of immigrants.

The Danish government has put an immense amount of work into making Copenhagen the "world's best cycling city." The Bicycle Account, published by the municipality in 2019, reports that while almost half of the city's residents cycle to their work or place of education every day, $27 \%$ drive and only $18 \%$ take public transport (Technical and Environmental 
Administration 2019,6). Since 2009, the city, the state, and private foundations have invested around 2 billion Danish kroner (230 billion GBP) in cycling-related initiatives. These include independent projects, building infrastructure, traffic safety measures, and planning safer routes. Through these projects, the city aims to reduce $\mathrm{CO} 2$ output and increase the health of the population. Most choose to cycle because the city's infrastructure is designed to make cycling the easiest form of transportation compared to driving or public transport. Advanced cycle paths (see figure 2) cut down on travel time significantly, cycling is much cheaper than public transport, and a bike is easier to park than a car. The Bicycle Account briefly touches upon cycling and immigrants, stating that almost half of Copenhageners originating from countries without a strong cycling culture never cycle. More than half of the population who never cycle are women, either because they do not know how to or because they feel insecure in traffic (Technical and Environmental Administration 2019, 12-27). The Account acknowledges the existence of cycling courses that teach women how to cycle to increase employment opportunities and improve health, but it does not provide details. Moreover, most of the existing cycling initiatives are geared toward those who can already cycle rather than those who are still learning.

\section{Mobility: Physical and Social Movements}

Mobility is more than just physical movement (Salazar 2017, 5). Lelièvre and Marshall (2015) differentiate between the two by deeming movement to be an object of observation while mobility is an object of study. According to

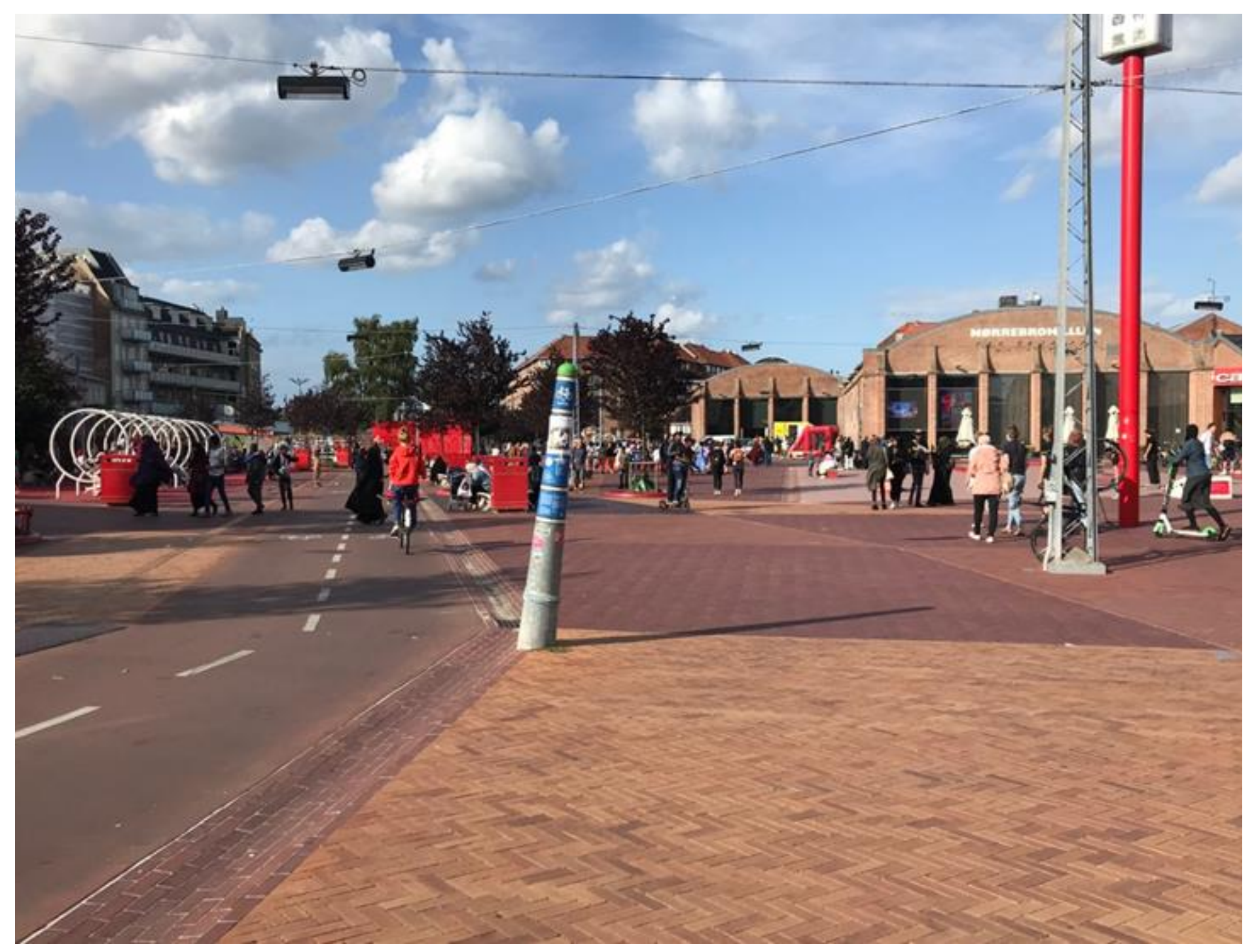

Figure 2: The Copenhagen Cycle Highway crosses through a lively square in the city. 
Lelièvre and Marshall, the former is therefore abstract and devoid of meaning, whereas the latter is socially constructed. Despite this difference, the terms are mutually dependent: "mobility, as the analytical object of study, can only be approached by bringing into dialogue the practices, perceptions, and imagined conceptions of movement" (Lelièvre and Marshall 2015, 440). Similarly, Peter Adey (2009) defines mobility as a lived relation both to oneself and to the world; it is how we understand and engage with the world around us analytically. It is a concept widely used to understand world processes such as migration (Adey 2009, xviii). In "Toward a Politics of Mobility," Cresswell (2010) identifies mobility as the "fragile entanglement of physical movement, representation and embodiment" (18). Representations of movement are what gives it meaning, physical movement means getting from point $A$ to $B$, and embodiment is the bodily experience of movement. These three aspects of mobility, Cresswell writes, are highly political (19). In another approach, Salazar (2017) distinguishes three characteristics of mobility: the ability to move, the ease or freedom of movement, and the tendency to change quickly (6). Yet mobility achieves little without being materialised through people, objects, words, and other embodied forms. Salazar (2017) states that mobility is an important part of how we belong in society, and it has different meanings depending on the social circumstances. There are many ways in which mobilities and movements can be studied analytically, and these will be explored further below.

Social inclusion and exclusion should be considered when studying social mobilities, as these can have a substantial impact on one's access to social services, jobs, education, and social networks, among other things. Social inclusion and exclusion can, for example, be linked to mobility through the notion of physical access (Cass et al. 2005, 539-40). The inability to access social services, goods, and places of work or education contributes to social exclusion, especially because they "appear to determine full membership or citizenship" (Cass et al. 2005, 540). In other words, access through physical mobility is beneficial for integration and, consequently, for moving forward into society. Women are more prone to social exclusion as their mobilities differ from those of men, and as a consequence, whether intentionally or not, their needs are not considered. The social exclusion of women occurs through transport, technology, social policies, and labour markets, to name a few examples. While the types of transport men and women may use differ, women's daily travel patterns are generally much more complex than those of men. A woman's commute may involve "dropping children off at school before going to work; taking an elderly relative to the doctor and doing the grocery shopping on the way home" (Criardo-Perez $2019,50)$. Men, on the other hand, are more likely to only travel between work and home, commuting with less diversions. There needs to be a greater awareness of this gendered difference, as urban planning and policies prioritise "compulsory mobilities," i.e. trips for educational or work purposes. Not only does this dismiss characteristically "female" activities of caregiving as unimportant, but also it specifically ignores the mobilities of women. Urban planning policies in most countries do not prioritise pedestrians and public transport users, and so women as the most likely persons to use these forms of transport are excluded (Criardo-Perez 2019, 50-57). The Red Cross cycling groups work to combat social exclusion by creating more opportunities for women to become mobile. Cycling as a form of transport provides a greater sense of freedom and provides independence from other modes of transportation that are more expensive and less flexible, especially in Copenhagen.

In sociological and anthropological literature, "social mobility" is often considered as the upward movement in society (Gans 2006; van den Berg 2011), often in terms of class and status within that society. Gans (2006) emphasises the role of class to bring upward mobility, as a higher class often means higher education and funds for training (154). He states that workplaces either create opportunities for or hinder upward mobility. This especially impacts migrants trying to assimilate or move upwards through employment (155). Gans claims upward mobility can lead to assimilation and vice-versa. In contrast, van den Berg (2011) criticises the 
use of social mobility as solely focused on education and employment. She calls for alternative uses and claims that subjective definitions and individual experiences researched through qualitative methods should be considered in the study of mobility, as this approach is broader and allows for alternatives. While I agree that subjective definitions and experiences are important to consider, van den Berg's (2011) definition still focuses on social mobility as an upgrade of class or "moving up the social ladder" (504). I argue that this definition is limiting and does not consider the other types of experiences of mobility, like those of migrant populations, which may describe a change but not an upward or downward movement in their class status. Therefore, definitions of social mobility must be expanded.

Migration is one of the key types of mobilities studied in anthropology, along with transport and movement (Cresswell 2009, 18). These studies are not a new phenomenon within anthropology; as Malkki (1992) writes: "People have always moved" (24). Yet what is new and always changing are the analytical approaches to mobility (Cresswell 2010; Malkki 1992). The context of migration studies has also been changing, especially in recent years as "increasing migration and ethnic diversity have become the norm" (Olwig and Paerregaard $2011,2)$. Therefore, some social scientists claim that migration and mobility should be seen as the natural state of humanity rather than stability (Samers 2010, 4). Horevitz (2009) favours the term "migration" over "immigration" in the anthropology of migration, as the former connotes a state of impermanence and continuous movement between home and host countries. In contrast, "immigration" suggests a stationary state of settling permanently in one country (Horevitz 2009, 78). Migration involves movement as one place pushes people out and another pulls people in (Cresswell 2009, 18). On one hand, this movement is physical. On the other, migration incorporates social mobility: the changing of one's position within society, from migrant to citizen. This change is not necessarily an upgrade in class, which further demonstrates why the definition of social mobility needs to be expanded.
Migration is not the only type of mobility relevant to migrants that needs to be discussed. We need to consider what occurs after migrants have already reached their destination: internal mobility within their new country of residence. Migrants continue to experience mobility long after the initial move as they navigate new social, economic, political, and cultural standpoints of their host country. One main form of internal mobility is integration. This concept describes a person's movement as their status is changed from being foreign in society to an active member and citizen of that society. Integration is a form of social mobility; however, it does not necessarily align with the previously mentioned definitions of social mobility in social sciences. Becoming integrated does not mean you are moving up or down the social ladder, since integration is an ongoing process, and the notion of what being integrated means is subjective. It is, therefore, problematic to measure integration in terms of success or fulfilment of certain attributes outlined by the state, such as involvement in after-school activities or the freedom to choose one's partner (Beskæftigelses og Integrationsforvaltningen 2018a). In this dissertation, class categorisation is not significant and is restrictive because it creates unnecessary divisions between people. To rethink the concept of social mobility, I define it as a movement into rather than upward. Integration is a movement into society because this process involves immersion into a place and the bridging of different cultures. Therefore, integration as a social mobility is not an upward movement but a movement forward into society.

\section{Academic Approaches to Integration}

Integration as a concept is difficult to characterise, and it is often used in a variety of disciplines, each using the term differently. That said, Grillo (2007) believes that we need to have a clear and shared understanding of what integration means, which differs depending on the context. The context of these concepts is important for examining what "happens on the ground" (981); in other words, context shapes how these concepts influence individuals (Grillo 2007). In the context of integration of 
immigrants, Samers (2010) outlines three principal meanings of integration: assimilation, multiculturalism, and the coming together of migrants and citizens. Assimilation puts the sole responsibility of integration and adopting values of the host country on the migrant. In contrast, multiculturalism and the coming together of migrants and citizens suggest that integration is reciprocal, and each has to accommodate the other (Samers 2010, 278). Similarly, Simonsen (2017) claims political integration to be a combination of assimilation and multiculturalism. Assimilation in this context is when immigrants resemble their host country as much as possible, whereas multiculturalism suggests immigrants follow the laws of the host country but maintain their own culture and way of living at the same time. For Simonsen, integration is a two-way process that involves both what the host state does and what the immigrants do (208).

Despite controversy about the exact terminology, Ager and Strang (2008) also regard integration as an important field to study. Their framework for successful integration consists of different factors of integration, with the foundation being citizenship. Employment, housing, health, and education are means of integration. Ager and Strang attempt to expand on usual political definitions by including experiences of migrants, social and cultural knowledge, and safety and security. Not one of these definitions states a definitive meaning but instead they suggest very specific approaches to integration. Samers (2010) and Simonsen (2017) approach integration similarly, whereas Ager and Strang (2008) create a framework that attempts to include as many aspects of integration as possible. The approaches all simplify the process of integration, which in reality is very complex. Defining the term in such specific ways can be problematic as it is too fragmented and non-linear. Integration is not something that can be broken down into bullet points. It is a complex process that is always changing. For this dissertation, I will consider integration to be the process of moving forward into society, which has all of the elements discussed above working together.
The meaning of integration in Denmark specifically has changed significantly since the concept first gained popularity within the Danish language in the 1950s. The term was not used in the context of migration until the first male guest workers entered the country in the 1960s and 70s. Since then, it has become pervasive in public and political debates (Rytter $2018,12)$. Contemplating how a specific society defines the process of integration is vital for understanding how the government of that society approaches integration. Current notions of integration in Denmark, according to Rytter (2018), are associated with values such as responsibility, self-sufficiency, and independence. These values reflect the emphasis on entering the workforce and language proficiency in integration policies because when a citizen can work, they are likely to be more self-sufficient and less dependent on welfare. Integration policies in Denmark have therefore generally aimed to help immigrants enter the workforce quickly. As a result, other factors that are necessary for a person to successfully integrate into society may be overlooked (Rytter 2018, 13-14). It is interesting to note that despite anthropological and sociological literature deeming integration as complex, confusing, and chaotic, the term is used regularly in literature published by Danish public institutions. Extensive information about integration policies, including the integration barometer and reports on official policies of the municipality, are freely accessible and easily found on the Copenhagen municipality website.

\section{Integration in a Danish Context}

The municipality of Copenhagen has created a barometer for measuring the process of integration with 26 goals to follow. Each of these goals is then labelled as having a positive change, a negative change, or no/little change in terms of successful achievement. Success is measured through quantitative research; for example, there was a $6 \%$ increase in participation in education of "non-Danes" from 2016 to 2014. Therefore, the goal to increase enrolment in schools was deemed successful. The more goals outlined in the barometer that are labelled as having a positive change, the more successful the process of integration in Copenhagen. The barometer highlights what it 
means to be an active Danish citizen: contributing to the economy, participating in cultural activities, and education are just a few of the main points. It also includes health and well-being and a sense of security within the city (Beskæftigelses og Integrationsforvaltningen 2018a). Along with the barometer, integration policies for the municipality of Copenhagen are published in a report every four years that outlines what has been done for integration in the past and what needs to be done in the future. The report consists of five benchmarks for successful integration, which are directed at what is needed for "Copenhageners with minority backgrounds," meaning immigrants or those descended from immigrants from nonwestern countries. The benchmarks include the following: minority citizens entering the workforce, performance in primary and secondary education, active participation in culture and communal activities, health and quality of life, and encouraging diversity in communities to prevent crime (Beskæftigelses og Integrationsforvaltningen 2018b, 18-12).

Cycling is mentioned briefly as a component for improving the health of the minority population, and the report claims that using bicycles as a form of transport leads to a healthier life (Beskæftigelses og Integrationsforvaltningen 2018b, 22). While not untrue, cycling as a form of transport does much more than improve a person's physical health. In other reports on integration, cycling is completely overlooked as a means to bridge different cultures and to create opportunities in the labour market. It is therefore not considered as a way to aid forward movement into society through integration as a form of social mobility. Policies are overlooking what I believe to be a useful tool for integration. These policies show that the process of integrating immigrants and immigrants' well-being are extensively deliberated within the municipality. Although the municipality has outlined specific goals and markers for integration, they are generalised and do not suggest how to achieve these goals. Completing successful integration, according to the reports above, seems to be put in the hands of local organisations and the immigrants themselves.
Moving forward to improve social science theories and government policies on integration needs to include a bigger focus on how these concepts may apply to people in daily life. My project aimed to understand how individual migrants feel about moving into a new country and the experiences they have in doing so. I started my fieldwork by asking the questions "what is integration?" and "do you feel integrated?" but quickly realised that these loaded questions were difficult to answer. Instead, I asked what their experiences as newcomers in Denmark were, what they needed to feel at home and welcomed here, and lastly, whether being part of the cycling group had any influence on their experiences. One of the most important things to feel at home in Denmark, for almost everyone I spoke with, was learning the Danish language. For some, being reunited with their families, especially their husbands, was what made Denmark home. Getting work as soon as possible was also seen as a way to settle into society, as this meant that migrants could earn an income and provide for their families while at the same time, being surrounded by Danish coworkers allowed them to become more familiar with Danish ways of life. These conversations put the process of integration into perspective. Although cycling was useful for getting certain types of work, especially in social health care, integration for these women was multifaceted and seemed to be an ongoing process.

One of the cycling trainees, Lola (see table 1), told me that one of the main things that made her feel at home in Denmark was religion. She moved here in 1993 from Armenia and is an orthodox Christian. Therefore, Lola felt comfort in the fact that many Danes are Christian as well. Understanding the language was also central for her, and as she was previously a language teacher, she found joy in the process. Learning how to cycle had not been a priority when coming to Copenhagen, but she was convinced to join the course with her daughter who wanted to learn so that it would be easier to meet up with friends. Lola wanted to learn not only so she could get around easier but also to stay fit. Ultimately, Lola saw biking as a form of sport or leisure activity and was therefore not as devoted to cycling lessons as her 
daughter. Brianna, another informant, told me that the most important thing for her to feel at home was to have her family reunited. She had just moved to Copenhagen seven months before I had met her. Brianna and her four-year -old daughter had come to Denmark from Pakistan so they could be together with her husband, who had been studying at a university here. Brianna wanted to build a happy family with her husband since taking care of her daughter was difficult for her to do alone in Pakistan. Siri, however, prioritised being surrounded by Danish-speaking people in order to feel more rooted. She had been in and out of the hospital the first years she was in Denmark and looked back on the experience very positively. Siri told me that if she had not been surrounded by Danish doctors, nurses, and patients, she would not have felt as comfortable living here.

Before every cycling session, Sandra and Brianna would meet up to practise Danish together. Brianna's husband did not want to pay for language classes as he thought they were too expensive. So, Sandra had gotten her hands on one of the course books from another cycling pupil and started practising with Brianna. She was inspired to eventually create a language café so that others in the same situation as Brianna have better opportunities to learn Danish. By the end of my time as a cycling teacher, Brianna had finally started Danish lessons and was quickly improving. From the women I spoke to during my fieldwork, I learned that they all had various and distinctive needs for them to feel like Copenhagen could be their home. Their stories demonstrate that the concept of integration cannot be condensed into a few approaches, and it is important to take individual perspectives into account when defining the approaches to integration that the city and various organisations take.

For cycling to be a way for the local municipality to assist migrants in achieving integration and social mobility, one of the most important things for the Employment and Integration Administration to consider when creating policies is that migrant women who learn how to cycle gain further opportunities through this skill. Many needed to cycle to get work or school, to pick up their children, to go to the grocery store, and to be part of events or other activities. Learning how to cycle helps migrant women to blend into the landscape of the city amongst the many other Danes on bikes, becoming part of the city's social fabric and moving forward into Danish society as a result. This is how the aspect of physical mobility, cycling to gain access, works together with social mobility in enabling integration into society. Not only does cycling help in the process of integration but also being in a group that meets once a week supports migrants' experience of integration as well. The women enjoyed coming to cycle classes not just to learn a skill but to talk to other people in similar situations and to get to know Danish people who can help them navigate a new culture they are not used to. Sandra made sure to create an atmosphere during the class that felt safe, welcomed everyone, and did not judge anyone based on their skill level or where they were from. She served coffee and tea at every session, greeted everyone with a big smile, and at the end of the day made sure to say goodbye personally to every participant as they left. As the team leader, she took on an almost motherly role. As such, the cycling course provided women with a group through which they could empower themselves by learning a skill critical to moving forward in Danish society. Moreover, by meeting others going through the process of integration, the women were able to create valuable connections and foster a sense of solidarity within the group.

\section{The Impact of Gender}

Different genders and the relations between them are products of social and cultural processes (Moore 2002, 815). The difference between men and women are not just biological features but originate from how gender is culturally constructed within societies. Although understandings of gender and sex vary depending on different cultures, each culture has its own way of referring to them. The constructions of gender are a way of making sense of our bodies, giving meaning to them and their embodied practices (Moore $2002,819)$. The concept of gender can refer to how social life is structured, as it is an ongoing process that plays an important role in 
organising our behaviour and thought (Mahler and Pessar 2006, 29). In this dissertation, the concept of gender will be used to discuss the experiences of women's mobility and how those experiences may differ because of their gender. Looking at the relationship between gender and mobility can provide insight into what limitations there are to mobility that stem from gender constructions and what can be done to overcome these limitations. In particular, my fieldwork allowed me to consider how of the relationship between gender and mobility effects migrant women in Copenhagen since all informants in this dissertation are female. The course I volunteered for was mainly created for women, but anyone was welcome to participate. However, Sandra believed grown men and especially husbands could dampen women's spirits while learning to cycle.

Women have only recently been considered in mobility and gender studies. Abbott and Payne (1990) state that women were not considered in these studies beforehand because mobility was originally measured by social class and occupation of the household leader, which has typically meant the man of the house (13). Women in migration and mobility studies have been overlooked due to the assumption that women migrate to accompany their providing husbands (Mahler and Pessar 2006, 27). Although this has been the case in the past, defining women migrants' motivations through these assumptions can generalise and simplify the experiences of women. Furthermore, studying only men ignores the fact that women and men move differently and have different needs for mobilities. Therefore, it is necessary to focus more on gender within the field of mobility studies. The impact of gender on the process of integration, or forward movement into society, is significant in the context of this dissertation as almost all of the people I spoke to during my fieldwork were women. Studying the relationships between gender, mobility, and integration are essential to gain a better understanding of the processes involved.

Gender can influence mobility by determining its patterns or, in terms of where someone might go or what type of transport they use, gender may limit mobility. At the same time, mobility can influence gender through empowerment and the shaping of identities. According to Hanson (2010), mobility is connected to questions of identity such as "who am I?" and "what can I accomplish in life?" Mobility is a way for women to enter public spaces and seek out more opportunities outside of the home, and they can therefore challenge traditional gender roles that define their lives (9). The experiences of female mobility are considered different and more restricted than that of males. Cresswell and Uteng (2008) note this restriction in the forms of transport men and women traditionally use. Men often travel more directly but longer distances by car. The car represents a masculine mobility in the form of freedom, sexual conquest, and aggression. Women, on the other hand, were encouraged to use a bus, a slower and more public form of mobility that was said to be more appropriate for household tasks within a limited radius (4). This leads me to question whether an increased sense of mobility can empower women.

Although European host societies tend to offer migrant women more freedom and mobility than their country of origin, these women often have a limited or disadvantaged position in this new labour market (Morokvasic 1993, 474). Following the labour migration stop of the 1970s in Europe, more women started migrating to join their husbands who already worked abroad. Due to specific labour demands and immigrant women's lack of recognised skill and education, they often found themselves in low-skilled, low-paying jobs with limited opportunities to increase their social mobility (Morokvasic 1993, 465). Women's work was seen as an extension of their domestic roles, and as a result, their activity became linked to their gender. This ideology pigeonholed them into specific occupations that were very similar to their domestic roles (Morokvasic 1993, 471). The discrimination and oppression women face in the labour market create barriers to their social mobility. Morokvasic, however, states that women do not need to accept the barriers to mobility. They can find strength within oppressive conditions. Women form groups that provide solidarity beyond the ethnic groups they are bound to, which she believes is an important aspect in the process of 
integration. She claims that immigrant women's resistance to the oppressive nature of the labour market is the basis for change in gender relations and social relations rather than adopting the values of a host country (Morokvasic 1993, 476). Is Sandra's cycling course, then, a form of group solidarity that assists migrant women who are trying to integrate into Denmark?

Many of the women I spoke with who participated in the course had moved to Copenhagen because they wanted to join their husbands who were either working or studying in Denmark. Although they followed their husbands who were already employed in Denmark, many of the women were learning how to cycle to assist in providing for their families. It is fairly common for immigrant women in Denmark to become "sosuassistenter" (social and health care assistants), as there is a lack of social health workers across Denmark, and the work can lead to other careers in the health sector without the need to attend university. Morokvasic's (1993) work, however, suggests that many women may become sosu-assistants because the work involved is similar to traditional gendered domestic roles. Sandra shares this view with Morokvasic. She thinks many of the women who come to the cycling course work in homecare because of the "motherly instinct" that comes naturally to them, and therefore the work attracts them. She also told me that it is not a job that many Danish people want since it is not seen to be prestigious. Two women I spoke to during the cycling training were in the process of becoming sosu-assistants. This was also why they were learning how to cycle, as it was mandatory for the work they would eventually do. Even though they both had working husbands and one woman even had a small child, they wanted to participate in providing for their household. Learning how to cycle gave them the ability to do so. Not only would they be contributing to the family income, but also working and moving around the city could help them move forward into society. These women were empowered by the cycling course and its volunteers to increase their physical mobility, which in turn helped them to achieve social mobility.
There is no lack of attempts to create policies that enable successful integration of migrants in Copenhagen, but very few of these are specifically targeted at women. Nongovernmental organisations and local initiatives make up for where the government is lacking in reaching female migrants, often sponsored by municipalities. The Red Cross is one of many organisations that has initiatives aimed at women, such as the Women's Network and the bicycle training programme. The cycling initiatives like the ones funded by the Red Cross are a great example of a way women may be empowered. As seen in figures 3 and 4, women at different levels of cycling were empowered though coaching and encouragement by volunteers. Many of the women I spoke to during my fieldwork did not have the chance to learn how to cycle in their home countries before they came to Copenhagen, but getting that chance now was empowering for them.

Kyra, who is originally from India, brought her visiting mother to a cycling lesson. Kyra's mother told me that she was not allowed to learn how to cycle as a child, even though her brothers were able to. When she was little, she

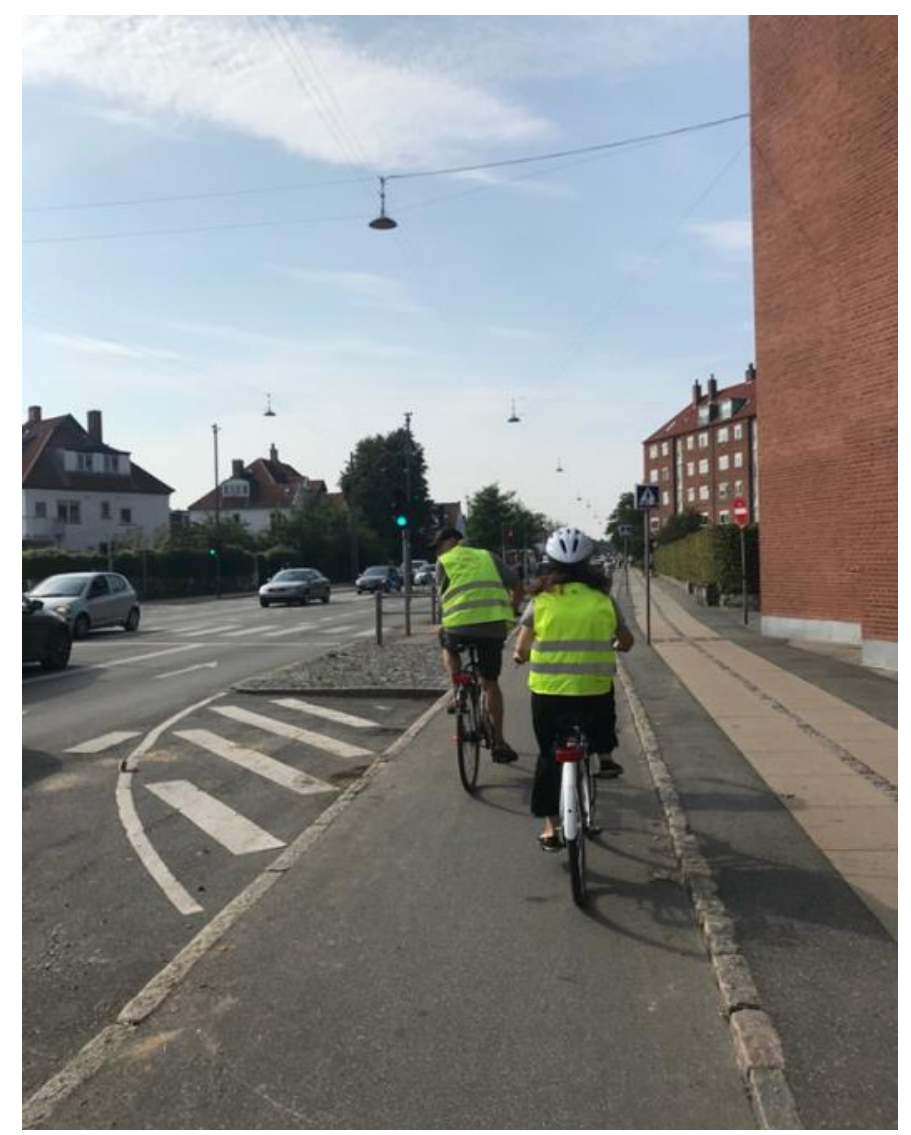

Figure 3: One of the volunteers leading a more advanced cyclist through traffic. 
would hop on her brother's bike but was never allowed to start or stop by herself. Instead, the brothers would place her on the bicycle and lift her off again. She had almost learned how to cycle but was never given the freedom over her own mobility on a bike. She was prohibited from biking as a child, and then she was limited by the protectiveness of her brothers. Because of this, she was not able to pass on the skill to her daughter, Kyra, who took the task into her own hands as an adult by joining the cycling course in Copenhagen. Kyra had been absent from the cycling classes for almost a month, and when she returned, she seemed very nervous to get on her bike again. Towards the end of the two-hour session, her feelings of anxiety had clearly vanished, and she even insisted on staying on the course for a few more minutes after the session had ended. Around and around she went on the little playground while the remaining volunteers watched. She was much more confident in herself now. As she sped up, her smile widened and her hair beneath her helmet flowed in the wind. "WOOOOO!" she yelled while pumping one fist in the air. Kyra eventually learned how to cycle home and around her neighbourhood after twelve classes and found cycling exhilarating.

A similar experience was described by another participant who had been a part of the course for around ten weeks and was an enthusiastic cyclist. Although Brianna had only been in Copenhagen for a short time, she was set on cycling around from the beginning. Most other participants had lived here for several years before joining the course, learning Danish first and getting familiar with the country. Learning how to bike had been a big wish of Brianna's since childhood. She told me that girls do not have the chance to learn back in her home country, Pakistan. After moving to Denmark to unite her family, Brianna told me that her first demand to her husband was to get the chance to learn how to cycle. Her husband agreed, so Brianna took the opportunity to break the barriers of mobility that she had in her home country and eventually overcame them. When I arrived, she was already proficient but still came to every single session. Brianna even started bringing her daughter who would pedal around on the cycle with help from other volunteers. She made sure her daughter would not experience the same kind of mobility restrictions as Brianna had when she was younger.

Sandra retired at a relatively young age and has a lot of time to dedicate herself to the cycling course as a volunteer. She is very committed to these women and passionate about helping them in any way she can. Sandra mentioned her aim was entirely to teach women how to bike, and the reason she wanted to do this was to help immigrant women specifically. She never banned men from participating in the course but preferred that they did not join since it changed the atmosphere of the lessons. These women came from different backgrounds and each was a different age, but they all came together to reach a shared goal: to learn how to cycle. In an interview I did with Sandra, she told me her reason for focusing on women so much is because she feels a sense of duty toward them. She wants to show them that their lives in Denmark can be vastly different than what they are used to and make them aware of the opportunities they can have here. Sandra wants to give these women confidence and believes that if they learn how to cycle, they will acquire the confidence to do more beyond the cycling lessons. Putting women in contact with their bodies and the element of encouragement pushing them to do more is what is empowering about the cycling course, and Sandra wants the women to know that they have power. Mobility can influence migrant women's perception of their gender roles by providing them with a sense of empowerment.

\section{Conclusion}

For two months, I volunteered with the Red Cross as a cycling instructor to get to know migrant women, their experiences coming to Denmark, and how they coped with moving and settling into a new country. From the women I spoke to, I learned that the process of integration cannot easily be condensed into a list of definitions and goals determined by academics and public policies. Their individual experiences are varied. Integration is a hard term to pin down, as the term means different things in different contexts and is even widely 


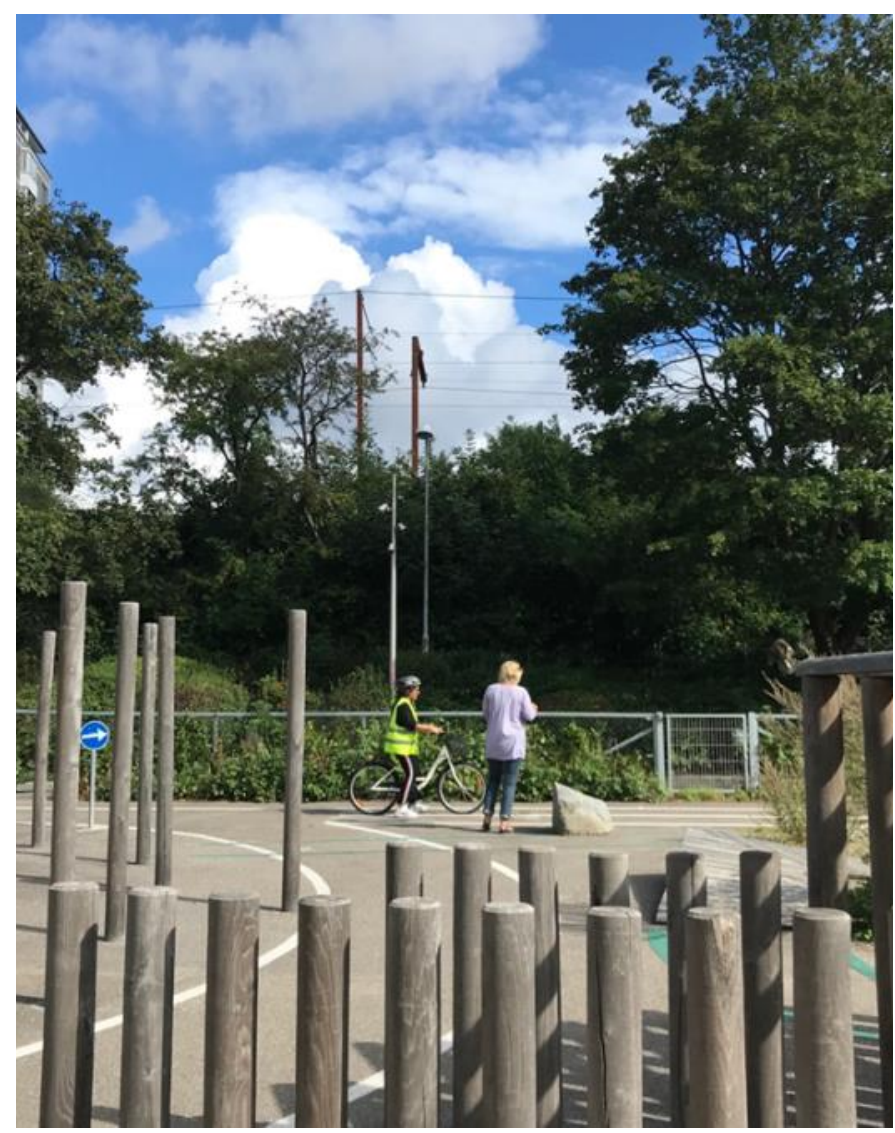

Figure 4: Sandra in action, teaching a beginner the basic steps.

debated in anthropology. "Do you feel integrated?" is a complicated and perhaps too simplistic question to ask. I started wondering what it means to feel at home, to feel settled in, and to have a sense of belonging in a place. Every person I spoke to answered this differently. Some said they needed to speak the language, others prioritised being with family, whereas one person felt more at home among Danes because they had the same religious beliefs. Being friends with Danish people, having an official residence permit, or working in Denmark were also essential elements. This dissertation barely scratches the surface of what is important for integration and feeling at home somewhere.

The male perspective has always been dominant in studies of mobility and migration. This means women are often overlooked in research. Through this dissertation, I wanted to include perspectives that are often ignored and reconsider theories that have been proven to be limiting and generalising. I attempted to rethink conceptions of mobility and integration to examine the individual experiences of migrant women. I started this project by asking: what is integration and how is it perceived by migrants? This thought became less prominent throughout my fieldwork than the actual processes that are involved in and impact integration. I argued that integration is a form of social mobility; it is a way of moving forward into society. At the same time, the process of integration is aided by other forms of mobilities, both physical and social. The physical mobility of cycling through Copenhagen makes easy access to public amenities, schools, and places of work possible. It creates opportunities within the labour market since some jobs, such as health care assistants, require applicants to be mobile. Thus, the physical act of cycling increases social mobility and furthers the process of integration. Cycling also impacts social mobility through embodied experiences. These experiences connect people to the environment and people around them, transform their identity, and create a sense of belonging to places.

My fieldwork clearly shows that gender has a substantial impact on mobility. Women I spoke to revealed that they had limited mobility in their countries of origin. Many of them were not allowed to cycle whereas their male relatives were. Gender also impacts social mobility, as much of the work immigrant women chose to do is related to common stereotypes of women's work. Perhaps this is because they are more likely to get this kind of work because it does not require higher education levels, which many immigrant women do not have. However, these jobs are low-paid and looked down upon by Danes. Therefore, a group like Sandra's cycling course is important for immigrant women. It brings them together and creates a sense of solidarity, which in turn empowers them and helps them to feel more at home and comfortable in a new country.

Cycling is a specific skill that is quite easy to teach, and so enabling immigrant women to acquire the skill has a very high success rate. Therefore, it is a straightforward way to approach the problem of limited mobility. While I believe that cycling is important for integration in this context, it would be wrong to assume that it would have the same effect anywhere else. For the women I spoke to specifically, the 
embodied act of cycling and participating in a communal activity was a good way to settle into Copenhagen; however, I acknowledge that the process of integrating and migrating to a country is incredibly complicated. For a person to feel a sense of belonging and achieve social mobility, much more is involved than what is outlined in this dissertation and cannot be achieved just by learning how to cycle. Cycling is a very small part of what is needed in the grand scheme of integration and social mobility in Denmark but important for the individuals involved in this research. 


\section{Acknowledgements}

First of all, I want to thank all of the wonderful women at the cycling course who were kind enough to dedicate valuable time talking to me, which they could have spent learning how to cycle. I want to thank Susanne for welcoming me as a volunteer and giving emotional support during this whole process. I am grateful to the Red Cross Copenhagen for allowing me to volunteer. To my supervisor, Tanya Argounova-low, I very much value the many helpful meetings and guidance I received. Lastly, I want to thank my parents for all of their kind words and encouragement. 


\section{References}

Adey, Peter. 2010. Mobility. London: Routledge.

Ager, Alastair, and Alison Strang. 2008. "Understanding Integration: A Conceptual Framework." Journal of Refugee Studies 21 (2): 166191.

Beskæftigelses og Integrationsforvaltningen. 2018a. "Integrationsbarometer 2018." Københavns Kommune, 1-40. Accessed June 17, 2021.https://www.kk.dk/sites/default/files/ integrationsbarometer_2018.pdf.

Beskæftigelses og Integrationsforvaltningen. 2018b. “Københavns Kommunes Integrationspolitik 2019-22." Københavns Kommune, 4-27. Accessed June 17, 2021. https://www.kk.dk/sites/default/ files/uploaded-files/integrationspolitik_fd.pdf.

Cass, Noel, Elizabeth Shove, and John Urry. 2005. "Social Exclusion, Mobility and Access." The Sociological Review 53 (3): 539-555.

Cresswell, Tim. 2010. “Towards a Politics of Mobility." Environment and Planning D: Society and Space 28 (1): 17-31.

Cresswell, Tim, and Tanu Priya Uteng. 2008. Gendered Mobilities. London: Routledge.

Criado-Perez, Caroline. 2019. Invisible Women: Exposing Data Bias in a World Designed for Men. New York: Abrams Press.

Danmarks Statistik. 2019. Indvandrere i Danmark 2018 Revideret. København Ø: Danmarks Statistik, 7-20. Accessed November 14, 2019. https://www.dst.dk/Site/Dst/Udgivelser/GetPubFile.aspx? id $=32561 \&$ sid=ind 2018 rev.

Folketinget. 1983. "Udlændingeloven af 8. juni 1983." Danmarkshistorien.dk. Last modified August 25, 2011. https:// danmarkshistorien.dk/leksikon-og-kilder/vis/materiale/ udlaendingeloven-af-8-juni-1983/.

Gans, Herbert. 2007. "Acculturation, assimilation and mobility." Ethnic and Racial Studies 30 (1): 152-164.

Grillo, Ralph. 2007. "An excess of alterity? Debating difference in a multicultural society." Ethnic and Racial Studies 30 (6): 979-998. 
Hansen, Sara Mielcke. 2016. “Udlændingelove 1983-2002.”

Danmarkshistorien.dk. Accessed November 14, 2019. https:// danmarkshistorien.dk/leksikon-og-kilder/vis/ materialeudlaendingelove-1983-2002/.

Hanson, Susan. 2010. "Gender and mobility: new approaches for informing sustainability." Gender, Place and Culture 17 (1): 5-23.

Ingvorsen, Emil Søndergård. 2019. “'Paradigmeskiftet' vedtaget i Folketinget: Her er stramningerne på udlændingeområdet." $D R$, February 21, 2019. https://www.dr.dk/nyheder/politik/ paradigmeskiftet-vedtaget-i-folketinget-her-er-stramningerne-paa -udlaendingeomraadet.

Lelièvre, Michelle A., and Maureen E. Marshall. 2015. “'Because life it selfe is but motion': Toward an anthropology of mobility." Anthropological Theory 15 (4): 434-471.

Mahler, Sarah J., and Patricia R. Pessar. 2006. "Gender Matters: Ethnographers Bring Gender from the Periphery toward the Core of Migration Studies." International Migration Review 40 (1): 2763.

Malkki, Liisa. 1992. “National Geographic: The Rooting of Peoples and the Territorialization of National Identity among Scholars and Refugees." Cultural Anthropology 7 (1): 24-44.

Moore, Henrietta L. 2002. "Understanding Sex and Gender." In Companion Encyclopedia of Anthropology: Humanity, Culture and Social Life, edited by Tim Ingold, 813-831. London: Routledge.

Morokvasic, Mirjana. 1993. '"In and out' of the labour market: Immigrant and minority women in Europe." New Community 19 (3): 459-483.

Olsen, Theis Lange, Johan Blem Larsen, and Morten Kaus. 2017. "Indvandringen til Danmark vendt på hovedet de sidste 20 år." DR, February 25, 2017. https://www.dr.dk/nyheder/politik/ indvandringen-til-danmark-vendt-paa-hovedet-de-sidste-20-aar.

Olwig, Karen Fog, and Karsten Paerregaard, eds. 2011. The Question of Integration: Immigration, Exclusion and the Danish Welfare State. Newcastle Upon Thyne: Cambridge Scholars Publishing.

Rytter, Mikkel. 2018. "Made in Denmark: Refugees, integration and the self-dependent society." Anthropology Today34 (3): 12-14. 
Salazar, Noel B. 2017. "Key figures of mobility: an introduction." Social Anthropology 25 (1): 5-12.

Samers, Michael. 2010. Migration. London: Routledge

Simonsen, Thorkild. 2019. "Integrationsloven - Lov om integration af udlændinge i Danmark (integrationslov)." Retsinformation.dk. Accessed November 14, 2019. https://www.retsinformation.dk/ Forms/R0710.aspx?id=87620.

Simonson, Kristina Bakkær. 2017. "Integration af indvandrere i Danmark." Politica 49 (3): 207-226.

Technical and Environmental Administration. 2019. The Bicycle Account 2018: Copenhagen City of Cyclists. Copenhagen: Københavns Kommune. Accessed June 17, 2021. https:// cyclingsolutions.info/wp-content/uploads//2020/12/CPH-BicycleAccount-2018.pdf.

Tesfaye, Mattias. 2017. Velkommen Mustafa. 1st ed. Copenhagen: Gyldendal.

van den Berg, Marguerite. 2011. "Subjective social mobility: Definitions and expectations of 'moving up' of poor Moroccan women in the Netherlands." International Sociology 26 (4): 503523. 